\title{
Technical note: PaleoDataView - a software toolbox for the collection, homogenization and visualization of marine proxy data
}

\author{
Michael Langner and Stefan Mulitza \\ MARUM - Center for Marine Environmental Sciences, University of Bremen, Bremen, Germany \\ Correspondence: Stefan Mulitza (smulitza@marum.de)
}

Received: 20 May 2019 - Discussion started: 12 June 2019

Revised: 29 October 2019 - Accepted: 4 November 2019 - Published: 19 December 2019

\begin{abstract}
We present a software toolbox that allows the efficient collection, management and maintenance of larger paleoceanographic data sets. The program combines a graphical user interface (GUI) with a simple document-based database and functionality for visualization, stratigraphy (visual alignment and radiocarbon calibration), age modelling and efficient ensemble time-series generation to create larger homogenous data compilations. Data can be imported from Excel or text files, are stored locally in netCDF format and can be easily exchanged between collaborating scientists. Within a data collection, data can be imported either to proxy-specific sub-collections or to a multi-proxy ("miscellaneous") sub-collection that allows the import and management of any downcore data. A single age model is shared among all proxies of a core within a collection. The standalone software can be used with Windows and macOS and does not require web access. Installers of the current version for both Windows 10 and macOS including the $\mathrm{C}++$ code can be downloaded from https://www.marum.de/Stefan-Mulitza/ PaleoDataView.html (last access: 5 December 2019) along with a detailed user guide.
\end{abstract}

\section{Motivation}

Paleoenvironmental data provide valuable information on climate variability and the functioning of the Earth system on timescales not covered by instrumental data. Information on past climates is usually based on proxies, parameters like stable isotope or elemental ratios of organism remains or sedimentary components that are indirect representations of climate parameters. Proxy values can be translated into climate parameters via transfer functions (e.g. Wefer et al., 1999) or directly simulated in climate models (e.g. Paul et al., 1999). Proxies are usually measured on samples taken from stratified climate archives (e.g. marine sediments) that allow the derivation of a timescale through radiometric dating or other stratigraphic methods. Meanwhile proxy data are available in large quantities and with considerable coverage in time and space, which allows a detailed spatio-temporal investigation of paleoclimate evolution and variability. When compiled into homogenous and consistent data products with error estimates, paleoclimate data can provide useful information to benchmark climate model experiments. However, the compilation of paleoclimate data is often a difficult and time-consuming process. Paleoclimate data available from public databases (e.g. https://www.pangaea.de/, last access: 5 December 2019) preserve the state of the data at the time of publication, but they usually do not provide a standardized data format that would allow an automatic processing of the data into comprehensive and consistent products. In addition, proxy data from public databases are often incomplete or fragmented, and they can contain outdated age scales due to the availability of new radiocarbon calibration curves or reference curves that are published after deployment of the data set in a public database. Furthermore, compilations of paleoceanographic data are often difficult to assess with respect to the quality, resolution and stratigraphic integrity of the included records. Here we provide an overview on the free open-access and cross-platform software tool PaleoDataView (PDV) that allows the efficient collection, homogenization and visualization of marine proxy data. Our primary intention is to support a workflow that allows the creation of continuously updatable and transpar- 
ent data products, comparable to software (e.g. Ocean Data View, Schlitzer, 2019) or atlas products (e.g. Levitus, 1982) in oceanography.

\section{Description}

\subsection{Software architecture}

The program code has been developed in $\mathrm{C}++$ computer language using the cross-platform development framework Qt (http://www.qt.io/, last access: 5 December 2019). So far, PDV distributions have been released for Windows and macOS. A Linux version is planned at a later stage. PDV works with a document-oriented database. After import, data are locally stored in binary form as netCDF files (Rew and Davies, 1990) using the netCDF C++ library (Version 4.4.1.1, https://www.unidata.ucar.edu/software/netcdf/, last access: 5 December 2019). This format is machineindependent and self-describing and allows the storage of metadata. The use of a binary format is necessary to allow the fast reading/writing of data and the efficient storage of large amounts of data, i.e. the age ensembles resulting from Bayesian age-depth modelling. Data can be imported from specifically formatted Excel (*.xlsx) or text files (Fig. 1). For each imported record, two types of netCDF files can be created: a file with the proxy data vs. depth and a file with the stratigraphic/age data, if available in the import file. PDV connects the two file types via the core name. An identical core name for the age model and the proxy file is guaranteed when simultaneously imported from Excel templates, but it has to be ensured when files are added manually. Several proxy records can exist for the same core but only one age/age model file. Hence, when the age model is changed, it changes for all proxy records connected to the age file. To allow fast access to all data in the database (e.g. for plotting purposes), an inventory file containing the metadata of all records in the database is generated. Since all metadata are stored within the file header, netCDF files generated with PDV can also be added manually to the appropriate folder (e.g. when exchanged between collaborating scientists). PDV comes with an installer that extracts the necessary resources to the appropriate folder on your hard disk, including a set of published proxy data for testing purposes (see references and data sources in the data files). The source code of PDV is available under a GNU General Public License, Version 3 and can be unpacked during the installation process. The size of downloadable installers is $\sim 120 \mathrm{MB}$ and the installation of PDV requires about $1 \mathrm{~GB}$ of free disk space, most of which is required for data resources (e.g. temperature and salinity fields from the World Ocean Atlas).

\subsection{Software functionalities}

PDV provides specific functionalities needed to streamline the data collection and homogenization process. These include the following:

- The option to create multiple independent data collections with the possibility of switching between collections and proxies when using PDV.

- Data import/export can be carried out from/to specifically formatted Excel or text files. Proxy-specific template files are provided with the distribution. Imported data are saved in netCDF files. These files can be exchanged between PDV users and included in other collections by deploying copies in the respective folder of the PDV data collection.

- An import helper for text files downloaded from the PANGAEA information system (https://www.pangaea. de/, last access: 5 December 2019). Missing metadata can be added within the software.

- A zoomable map interface allows the user to quickly explore the availability of data in specific regions. Raw downcore data are plotted when a core position in the map is selected (Fig. 2). Alternatively, profile views with a similar functionality are available for major ocean basins.

- An editor for metadata. Metadata can be corrected/added and saved in the netCDF file of the record.

- There exists the possibility to comment and flag individual downcore proxy data. Comments (e.g. sediment disturbances) can be added to every sampling depth in a table view.

- There is an option to make clipboard copies of most of the displayed data via an inbuilt data viewer accessible through the context menu.

- A radiocarbon calibration tool allows the calibration of raw radiocarbon dates against IntCal13 (Reimer et al., 2013), taking custom or modelled (Butzin et al., 2017) reservoir ages into account.

- A visual alignment tool (comparable to AnalySeries, Paillard et al., 1996) allows the derivation of correlation ages from standard reference curves (e.g. Lisiecki and Stern, 2016) or from custom reference time series produced within PDV, optional in combination with existing calibrated radiocarbon ages.

- A map interface allows the fast visualization/comparison of modern ocean atlas hydrographies for the core sites and the global ocean (Antonov et al., 2010; Locarnini et al., 2009), including proxyrelevant parameters like $\delta^{18} \mathrm{O}$ of sea water (LeGrande 


\section{Structure and workflow PaleoDataView}

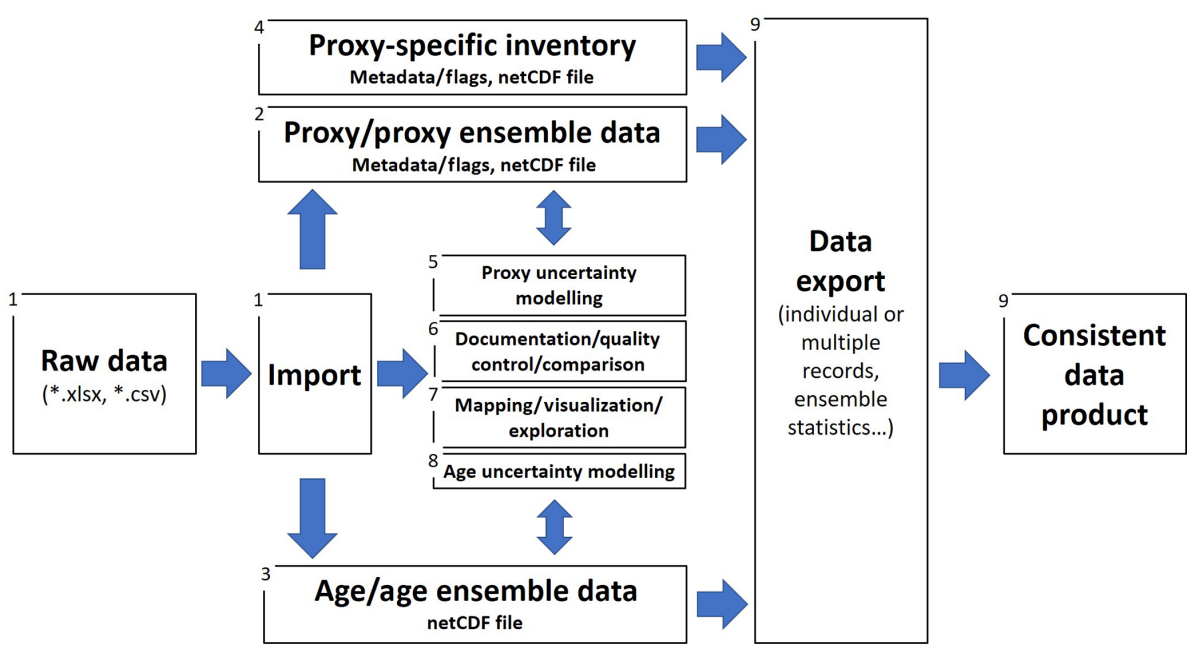

Figure 1. Workflow of the PDV-Toolbox. Data can be imported (1) from Excel or text files and are separated into a netCDF file containing metadata and downcore proxy data (2) and a netCDF file containing all age-related data (3). An inventory file is created (4) and constantly updated containing only the metadata of all records in the database. This file allows fast access to individual files in the database. Functionality within the toolbox includes proxy uncertainty modelling (5), commenting, flagging and documentation of data/metadata (6) and tools for visualization (7) and age modelling (8). Individual time series or proxy ensemble time-series statistics for individual or a collection of records can be exported in various file formats (9).

and Schmidt, 2006) and pre-industrial $\delta^{13} \mathrm{C}$ of dissolved $\mathrm{CO}_{2}$ (Eide et al., 2017).

- A tool to compare different proxy records in the time or depth domains.

- A direct interface to Bacon (Bayesian age modelling, Blaauw and Christen, 2011) including the option to store/reload age models and Bacon parameters in/from netCDF files.

- Proxy-specific tools to apply transfer functions or correct data. Proxy-specific tools will be activated when a proxy is selected.

- The calculation and visualization of time-series ensemble statistics derived from Bacon age models.

\section{Potential audiences and application scenarios}

\subsection{Data curation for individual scientists}

Individual scientists usually collect their published and unpublished data on their personal computers, often in the form of Excel or text files, with an arbitrary structure. However, the amount of data in paleoceanography and marine geology is increasing exponentially due to more efficient measurement techniques, including non-destructive downcore scanners. This makes it more and more difficult to keep track of the existing data, their characteristics and spatial distribution. Published data should in principle be available in public databases, but these databases are usually static and preserve the state of data and research upon publication. Data have to be downloaded before they can be investigated or modified, for example with respect to stratigraphy. Most scientists prefer to investigate and publish their data before deployment in public databases. This means that it can take years or even decades until newly produced paleoceanographic data are available in the public domain, and there is the risk of incomplete documentation or even data loss, i.e. if scientists retire. PDV combines a simple database with visualization and data analysis tools and helps to organize, document, compare and investigate individual data collections. PDV encourages the standardized storage of data at a very early state and thus increases the probability that unpublished data may finally end up in the public domain with the proper documentation.

The development of age models for sediment cores is a key technique to produce time series of past climate variability on longer time scales. However, since calibration and reference curves are constantly being improved, age models for individual cores need to be revised from time to time. PDV can be employed to efficiently create and update age models based on radiocarbon calibration or visual alignment to standard reference curves. Ages/age errors from other events (e.g. tephras or biostratigraphic dates) can be added manually in the alignment tool. Custom reference curves can be imported or created from records within PDV, i.e. for a regional 


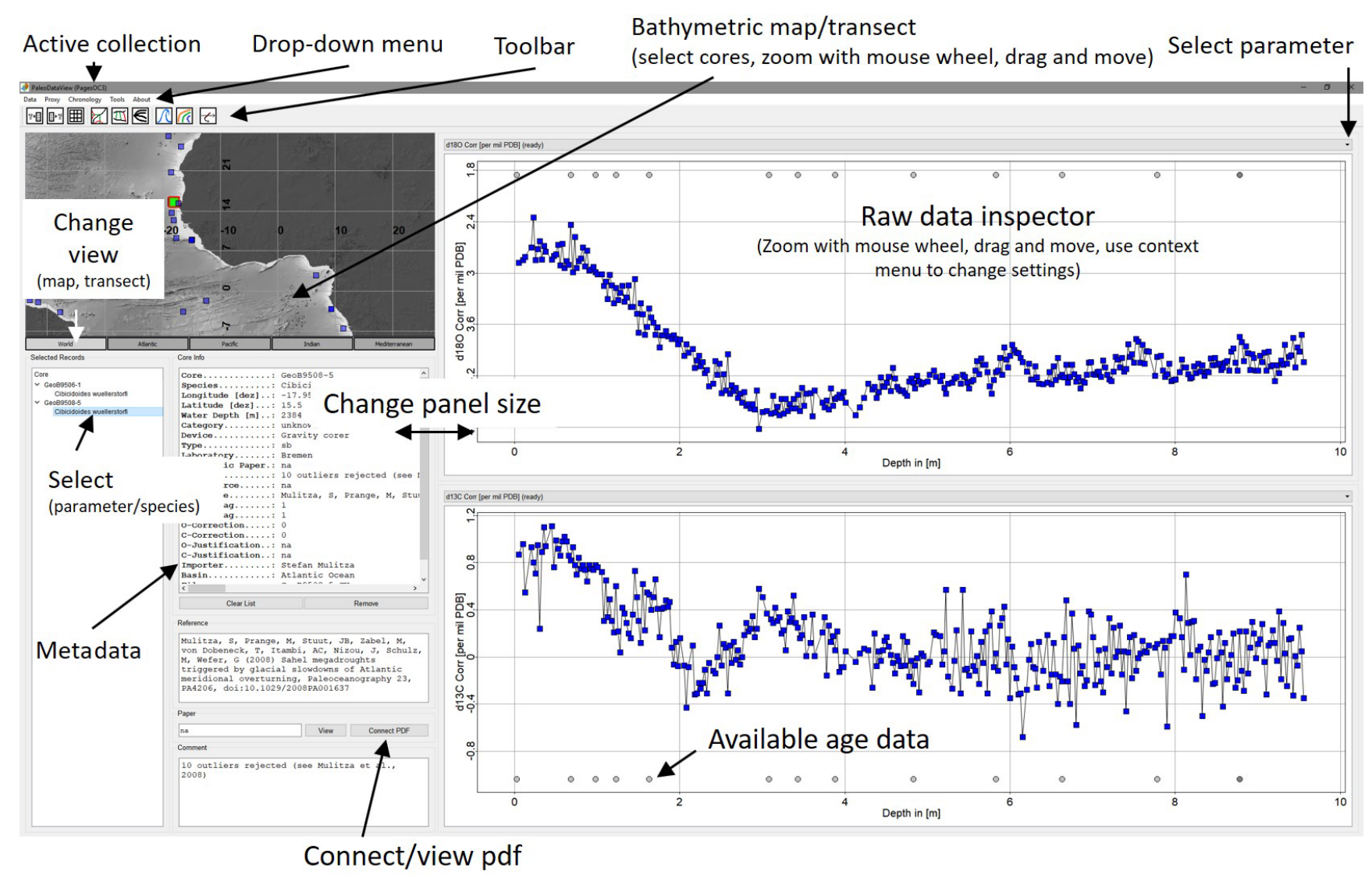

Figure 2. Main window of PDV. Core locations can be selected by pointing and double-clicking with the mouse into the map on the left panel. Both the graphics window and the map are interactively movable and scalable. Available datings/tie points are indicated by cycles at the bottom of the graph. A click on the individual data points reveals depth and isotope value. An available PDF document (i.e. from the corresponding publication) can be connected to the data set and viewed. Further functionality can be accessed through the menu or the symbol bar at the top of the window.

core-to-core correlation. An added value of PDV is that these dating techniques can be combined and that all details of age model production are preserved. Using the "Miscellaneous" proxy category (see user manual), PDV might be used as a simple dating tool for any downcore parameter.

\subsection{Development and maintenance of proxy-specific databases}

Millions of proxy measurements are available in public data libraries. For example, the databases PANGAEA (https: //www.pangaea.de/, last access: 5 December 2019) and NOAA (https://www.ncdc.noaa.gov/, last access: 5 December 2019) host foraminiferal stable isotope and radiocarbon data for thousands of cores, and this database is constantly growing. The combination of a simple documentoriented database with functionality for data processing and documentation allows the efficient collection and transformation of foraminiferal stable isotope and other proxy data into quality-controlled and homogenous compilations. Since all modifications are preserved and documented, it is possi- ble to efficiently update the proxy database and the resulting data product. A similar workflow is established in other instrumental data products such as the World Ocean Atlas, where the raw data (World Ocean Database, e.g. Johnson et al., 2009) and the resulting derived products (World Ocean Atlas, e.g. Antonov et al., 2010; Locarnini et al., 2009) are regularly updated as important resources for oceanography and neighbouring disciplines.

Since PDV does not provide a complex relational database, very specific database queries are not possible. However, the advantage of a document-oriented database is the exchangeability of the files among personal computers operated with Windows and macOS. For example, netCDF files can be exchanged among cooperating users of PDV via email or file server. The netCDF format is platformindependent and can also be processed with other software. If PDV data collections are published, they can be provided as a zipped collection and later easily be reviewed or extended by other scientists. 


\subsection{Educational and explorational use}

PDV also offers opportunities for educational purposes in the geosciences. Students can interactively explore the regional paleoclimate evolution, compare records from different locations and sedimentation regimes and test stratigraphic methods. Furthermore, PDV also comes with modern ocean atlas hydrographic data and allows the interactive exploration of the distribution of sea water properties, including proxyrelevant parameters such as $\delta^{13} \mathrm{C}_{\text {DIC }}$ and $\delta^{18} \mathrm{O}$ of sea water.

PDV might also be used as a tool for site survey planning (e.g. at the proposal stage to identity sampling gaps) or to find suitable coring sites before or even during marine expeditions (PDV does not require any web access and does not communicate via the internet). Finally, PDV can be used as a tool to discuss data with fellow scientists at meetings and workshops.

\section{Concluding remarks and further developments}

The combination of a proxy toolbox and a proxy database increases the transparency and reusability of proxy collections and increases the efficiency of the required homogenization steps. The current version of PDV includes proxy-specific functionalities for foraminiferal isotopes, foraminiferal $\mathrm{Mg} / \mathrm{Ca}$ and alkenones in addition to a "miscellaneous" proxy category for collections of unspecified downcore records. The "miscellaneous" category is relevant if the user aims at multi-proxy studies on single cores or downcore parameters for which no proxy category exists. We plan to extend future versions of PDV to include modules and functionalities for more proxies and downcore parameters. The built-in stratigraphic methods can also be extended and refined. The inclusion of a "classical" age-modelling module (e.g. Blaauw, 2010) with a simpler interpolation between dates would provide an efficient and more transparent alternative to Bayesian age modelling. The visual alignment with standard records might benefit from the inclusion of an automatic alignment algorithm such as dynamic time warping (Rabiner et al., 1978). Furthermore, we plan to include spatial interpolation methods (e.g. Schäfer-Neth et al., 2005; Troupin et al., 2012) to allow a budgeting or the creation of volume/area-weighted averages for specific parameters. Our overarching goal is to allow a workflow where the proxy values can be saved into organized and quality-controlled atlas products with the possibility to quickly review the raw data foundation. These atlases can then be very useful products for neighbouring disciplines such as paleoclimate modelling.

Code availability. Installers of the current version of PDV for both Windows 10 and macOS including the $\mathrm{C}++$ code can be downloaded from https://www.marum.de/Stefan-Mulitza/ PaleoDataView.html (last access: 5 December 2019) along with a detailed user guide that will be continuously updated. The source code and all resources needed for compilation can be unpacked during the installation process.

Author contributions. ML implemented the $\mathrm{C}++$ version of PDV. SM conceptualized the data base structure and basic functionalities of PDV in a Matlab prototype and wrote the paper with input from ML. Both authors contributed to the design of PDV.

Competing interests. The authors declare that they have no conflict of interest.

Special issue statement. This article is part of the special issue "Paleoclimate data synthesis and analysis of associated uncertainty (BG/CP/ESSD inter-journal SI)". It is not associated with a conference.

Acknowledgements. Comments by Ralf Schiebel and an anonymous reviewer substantially improved the manuscript. Thanks to Tilmann Schwenk, Lukas Jonkers, André Paul, Cristiano Chiessi, Janne Repschläger, Gema Martínez Méndez, Adegbola Ibrahim Akinola and working group 3 of the PalMod Project for discussion, bug reports and comments. This work was supported by the German Federal Ministry of Education and Research (BMBF) as a Research for Sustainability initiative (FONA) through the PalMod project (FKZ: 01LP1509B).

Financial support. This research has been supported by the Bundesministerium für Bildung und Forschung (grant no. FKZ01LP1509B).

The article processing charges for this open-access publication were covered by the University of Bremen.

Review statement. This paper was edited by André Paul and reviewed by Ralf Schiebel and one anonymous referee.

\section{References}

Antonov, J. I., Seidov, D., Boyer, T. P., Locarnini, R. A., Mishonov, A. V., Garcia, H. E., Baranova, O. K., Zweng, M. M., and Johnson, D. R.: World Ocean Atlas 2009, Volume 2: Salinity, NOAA Atlas NESDIS, edited by: Levitus, S., U.S. Government Printing Office, Washington, D.C., 184 pp., 2010.

Blaauw, M.: Methods and code for "classical" age-modelling of radiocarbon sequences, Quat. Geochronol., 5, 512-518, https://doi.org/10.1016/j.quageo.2010.01.002, 2010.

Blaauw, M. and Christen, J. A.: Flexible Paleoclimate Age-Depth Models Using an Autoregressive Gamma Process, Bayesian Anal., 6, 457-474, https://doi.org/10.1214/11-ba618, 2011.

Butzin, M., Köhler, P., and Lohmann, G.: Marine radiocarbon reservoir age simulations for the past 50,000 years, Geophys. Res. 
Lett., 44, 8473-8480, https://doi.org/10.1002/2017g1074688, 2017.

Eide, M., Olsen, A., Ninnemann, U. S., and Johannessen, T.: A global ocean climatology of preindustrial and modern ocean delta ${ }^{13} \mathrm{C}$, Global Biogeochem. Cy., 31, 515-534, https://doi.org/10.1002/2016gb005472, 2017.

Johnson, D. R., Boyer, T. P., Garcia, H. E., Locarnini, R. A., Baranova, O. K., and Zweng, M. M.: World Ocean Database 2009 Documentation, NOAA Printing Office, Silver Spring, MD, 175 pp., 2009.

LeGrande, A. N. and Schmidt, G. A.: Global gridded data set of the oxygen isotopic composition in seawater, Geophys. Res. Lett., 33, L12604, https://doi.org/10.1029/2006gl026011, 2006.

Levitus, S.: Climatological Atlas of the World Ocean, U.S. Gov. Printing Office, Rockville, M.D., NOAA Professional Paper 13, 190 pp, 1982.

Lisiecki, L. E. and Stern, J. V.: Regional and global benthic $\delta^{18} \mathrm{O}$ stacks for the last glacial cycle, Paleoceanography, 31, 13681394, https://doi.org/10.1002/2016pa003002, 2016.

Locarnini, R. A., Mishonov, A. V., Antonov, J. I., Boyer, T. P., Garcia, H. E., Baranova, O. K., Zweng, M. M., and Johnson, D. R.: World Ocean Atlas 2009, in: Volume 1: Temperature, NOAA Atlas NESDIS, edited by: Levitus, S., U.S. Government Printing Office, Washington, D.C., 184 pp., 2009.

Paillard, D., Labeyrie, L., and Yiou, P.: Macintosh program performs time-series analysis, Eos T. Am. Geophys. Un., 77, 379, 1996.

Paul, A., Mulitza, S., Pätzold, J., and Wolff, T.: Simulation of oxygen isotopes in a global ocean model, in: Use of proxies in paleoceanography, Springer, 1-68, 1999.
Rabiner, L. R., Rosenberg, A. E., and Levinson, S. E.: Considerations in Dynamic Time Warping Algorithms for Discrete Word Recognition, IEEE T. Acoust. Speech, 26, 575-582, https://doi.org/10.1109/tassp.1978.1163164, 1978.

Reimer, P. J., Bard, E., Bayliss, A., Beck, J. W., Blackwell, P. G., Ramsey, C. B., Buck, C. E., Cheng, H., Edwards, R. L., Friedrich, M., Grootes, P. M., Guilderson, T. P., Haflidason, H., Hajdas, I., Hatte, C., Heaton, T. J., Hoffmann, D. L., Hogg, A. G., Hughen, K. A., Kaiser, K. F., Kromer, B., Manning, S. W., Niu, M., Reimer, R. W., Richards, D. A., Scott, E. M., Southon, J. R., Staff, R. A., Turney, C. S. M., and van der Plicht, J.: IntCal13 and Marine13 Radiocarbon Age Calibration Curves 0-50,000 Years cal BP, Radiocarbon, 55, 1869-1887, 2013.

Rew, R. and Davis, G.: NetCDF: an interface for scientific data access, IEEE Comp. Graphics App., 10, 76-82, https://doi.org/10.1109/38.56302, 1990.

Schäfer-Neth, C., Paul, A., and Mulitza, S.: Perspectives on mapping the MARGO reconstructions by variogram analysis/kriging and objective analysis, Quaternary Sci. Rev., 24, 1083-1093, https://doi.org/10.1016/j.quascirev.2004.06.017, 2005.

Schlitzer, R.: Ocean Data View, available at: https://odv.awi.de, last access: 5 December 2019.

Troupin, C., Barth, A., Sirjacobs, D., Ouberdous, M., Brankart, J. M., Brasseur, P., Rixen, M., Alvera-Azcarate, A., Belounis, M., Capet, A., Lenartz, F., Toussaint, M. E., and Beckers, J. M.: Generation of analysis and consistent error fields using the Data Interpolating Variational Analysis (DIVA), Ocean Model., 52-53, 90-101, https://doi.org/10.1016/j.ocemod.2012.05.002, 2012.

Wefer, G., Berger, W., Bijma, J., and Fischer, G.: Clues to ocean history: a brief overview of proxies, in: Use of proxies in paleoceanography, edited by: Fischer, G. and Wefer, G., Springer, $1-68,1999$. 